\title{
Autogestión en la ciudad: la experiencia de la Asociación de Pobladores del sector «El Brillante»
}

Recibido: 20.07.18

Aprobado: 21.09.18

\author{
Huber Alvarado Castro \\ huber.alvacastro@gmail.com \\ Erick Moreno Avellaneda \\ Universidad Nacional Mayor de San Marcos
}

\begin{abstract}
RESUMEN
La Asociación de Pobladores del sector El Brillante es una de las experiencias de Comunidad Urbana Autogestionaria de Lima y de los lugares menos estudiados como caso social. Entonces, es pertinente la reflexión acerca de la gestión de la organización vecinal y los cambios que ha afrontado conforme a su local comunal, para ver a partir de ello los efectos del gobierno y los cambios en su estructura orgánica y la inserción de nuevos miembros de la directiva de la asociación.
\end{abstract}

Palabras Clave: Asociación de pobladores; Comunidad urbana autogestionaria; organización vecinal; toma de tierras; Izquierda Unida, Gobierno militar.

\section{Self-management in the city: the experience of the Asociación de Pobladores from «El Brillante» sector}

\begin{abstract}
The Association of Settlers of the Brillante sector is one of the experiences of the Urban Self-Management Community of Lima and of the less studied places such as the social case, at that moment the reflection on the management of the neighborhood organization and the changes that faced an agreement its local community, for from this, the effects of the government and the changes in its organic structure and the insertion of new members of the association's board.
\end{abstract}

KeYwords: Association of Settlers; Urban Self-managed Community; Neighborhood Organization; land seizure; United Left; Military Government.

1 Este reporte de investigación acción fue elaborado en el marco de las actividades del curso de "Teorías del Desarrollo" impartido en la Escuela Profesional de Sociología de la Facultad de Ciencias Sociales de la Universidad Nacional Mayor de San Marcos, en el ańo 2017. 


\section{Introducción}

A polinario Rojas Obispo, primer secretario general de la Comunidad Urbana Autogestionaria de Villa El Salvador (CUAVES), planteó alrededor de 1973 la siguiente reflexión a manera de interrogante: ¿¿Si existe comunidad campesina en los Andes por qué no puede existir una comunidad urbana? (Coronado \& Pajuelo, 1996). Esta provocadora pregunta exige respuestas: ¿Qué es una comunidad urbana? ¿Es posible relacionar su existencia con asuntos como la autogestión? ¿Podemos decir que existen aún la comunidad urbana autogestionaria?, y, en su defecto ¿Cuáles serían esos casos?

Primero hagamos la diferencia entre comunidad urbana y comunidad urbana autogestionaria (en adelante CUA), pues aunque ambos son organizaciones vecinales, la CUA ejerce una determinada autoridad sobre un ámbito territorial, organizado en sectores y manzanas delimitadas. Cuentan con un Comité Ejecutivo Central, Juntas Directivas para cada sector y para cada manzana. Además, César Germaná en 1994 le incluye Asambleas Plenarias donde participan otro tipo de organizaciones siendo femeninas las más importantes (Comedores Populares, Comités de Vaso de Leche y Clubes de Madres).

Germaná menciona a la autogestión como «el aspecto más significativo del desarrollo de una vasta red organizacional», esto constituye para él una respuesta de los sectores más pobres de la población para satisfacer sus necesidades fundamentales en los momentos en que el Estado deja de participar en la reproducción de la fuerza de trabajo y los trabajadores deben asumir sus propia subsistencia.

$\mathrm{Y}$ aunque las nuevas políticas neoliberales son para Germaná una oportunidad para la organización vecinal, en nuestra experiencia hemos visto que para que esto pueda mantenerse se requiere del Estado para reactivar la CUA, pues con el apoyo del gobierno pueden traerse grandes beneficios para la organización e institucionalidad de la CUA. Además es pertinente acotar su función de asociación, en la cual Meneses (1998) lo considera como de las primeras formas de organización que aparecen en las barriadas, las cuales surgen conjuntamente con la toma de tierras urbanas que darán lugar a la formación de ba- rriadas. Su finalidad es conseguir la estabilidad en el lugar ocupado para luego propiciar su desarrollo.

En este artículo vamos a comprender la CUA como la organización vecinal y/o asociación de pobladores que ha sido formada en tanto los procesos de toma de tierras en los ańos 70 y 80 les dieron las oportunidades para que la colectividad pueda mantenerse en relaciones económicas solidarias y recíprocas. Calderón (2016) menciona que según el Fondo Nacional de Salud y Bienestar Social las primeras asociaciones de pobladores datan de 1934; sin embargo, en los cincuenta estas organizaciones se multiplican hasta que en 1961 una ley del gobierno nacional legalizó las ocupaciones a las tierras privadas y públicas producidas hasta entonces y prohibió futuras invasiones.

Luego de las ocupaciones de 1934, tuvimos una época de conflicto entre el Estado y los ocupantes de tierras hasta el 5 de mayo de 1971 con la muerte de Edilberto Ramos Quispe, el cual provoca un cambio en el gobierno militar de Velasco Alvarado. Es así como el 14 de mayo de 1971 se da la primera generación de migrantes "por intermedio de las Fuerzas Armadas se ordena la reubicación de las primeras 2300 familias en la zona de la Tablada de Lurín, a $20 \mathrm{~km}$ al sur de Lima. Los camiones del Ejército facilitaron el traslado de los invasores al nuevo asentamiento, un arenal desprovisto de todos los servicios públicos elementales» (Blondet, citado por Becerra, 2017, p. 23) y en junio del mismo año se crea el Sistema Nacional de Apoyo a la Movilización Social (Sinamos).

Así, en 1971 la ocupación de los terrenos de Pamplona (el pamplonazo) empezó con 9000 familias en dos días y 11000 familias más en los dos meses siguientes, esto producto de las destrucción de los tugurios a partir del terremoto de mayo de 1970 (Calderón, 2016) y el excedente de otras barriadas formadas en décadas anteriores (Burga, citado por Becerra, 2017, p. 12).

Becerra (2017) dice que en julio de 1972, la organización de los habitantes realizando la primera convención de Villa El Salvador, asumió el nombre de Cooperativa Integral Comunal Autogestionaria (CICA), pero en noviembre de 1973 se realiza una asamblea de pobladores y dirigentes de grupos residenciales y manzanas cambiando el nombre a CUAVES (Comunidad Urbana Autogestionaria de 
Villa El Salvador). Coronado \& Pajuelo dicen que con esto se desempeńó toda acción relativa a la consolidación del asentamiento (problemas del suelo, vivienda, servicios básicos, etc.).

Coronado \& Pajuelo mencionan a Villa El Salvador mediante el contraste de dos períodos históricos, uno de 1971-1975 donde el modelo autogestionario comprende el tratamiento de su origen y desarrollo, tanto en las empresas autogestionarias de producción y servicios como en la reivindicación urbana, en los cuales la autogestión habría encontrado sus límites debido tanto a razones internas (gestión, pugnas de dirección) como externas (relaciones con el Estado, presión poblacional, etc.). El segundo modelo es del período 1984-1988 donde según Coronado \& Pajuelo generan una propuesta de cogestión con Izquierda Unida, es examinado mediante la atención en los cambios del diseño urbanístico original y de los proyectos productivos para la pequeña y micro empresa vía el parque industrial.

Por la necesidad de tierras que tiene la población, el gobierno de Velasco Alvarado aplica las Micro Áreas de Desarrollo (MIADES) en el distrito de El Agustino, esta era una articulación de ocho organizaciones vecinales (desde el Sector I al sector VIII) como objeto de convertirse en instrumentos de desarrollo integral, crear instancias centralizadas de la organización vecinal, hacer necesarias la instalación de las agencias municipales y facilitar el desarrollo integral de la planificación con las bases (Gómez, 2008).

Romero (1993) menciona como objetivo de la MIADES la integración de asentamientos con características y problemas semejantes para atenderlos colectivamente. Esta debe contar con una infraestructura vial integradora entre zonas, que garantice la existencia de un mercado local, un mínimo suficiente de mano de obra disponible, la existencia de materias primas o recursos propios, dentro de la subdivisión espacial de desarrollo y la existencia de servicios públicos.

Romero seńala dos etapas: primero con el proyecto de apoyo de Izquierda Unida, y luego con el ingreso de las ONG conformaron la Comisión Técnica Intercentros (CTIC). Se comprueba la existencia de coincidencias muy grandes en la perspectiva global del proyecto entre ONG y autoridades municipales; por ejemplo, en la necesidad de iniciar la articulación zonal a través de las vías integradoras, en la pers- pectiva del autogobierno, en hacer la MIADES una organización popular y en concebirla como germen de un nuevo Estado. Por eso, la CTIC y los centros prestaron especial atención a la formulación y aprobación de sus estatus. Leyéndolos, se percibe el acento puesto en la autogestión y el autogobierno y en el largo plazo.

A partir del Gobierno Militar de Francisco Morales Bermúdez se vio la necesidad de trasladar a 5000 familias que ocupaban terrenos entre el río Rímac y el Puente Huáscar el año nuevo (Fajardo, 2009). El Estado para esto ofreció trasladarlos, pudiendo escoger entre Pampas de los Perros (Ventanilla), Villa El Salvador, Morrón (Ate-Vitarte) y las Pampas de Canto Grande, finalmente decidieron por Huáscar por ser más cercano a los centros de trabajo y al Centro de Lima.

Es así como en 1976 fue creada la UPIS Huáscar (Urbanización Popular de Interés Social Huáscar), Arias (2012) refiere un proceso de asentamiento rápido, tras asignar los lotes tizados por sectores y sorteos, los servicios públicos (educación, salud, religión) se ofrecieron carpas, aunque no contaban con veredas, pistas, energía eléctrica, agua ni desagüe.

Arias dice que la UPIS tuvo en un inicio 171 ha de las cuales 112 ha pertenecieron a una antigua concesión minera, y 59 ha eran terreno apto para vivir. La habilitación urbana se vio truncado a partir de 1980. Aparte la habitación urbana no concluyo, por ello aún no se cuenta con todas sus pistas y veredas. Esta situación y la imposibilidad de obtener el título de propiedad del terreno, es una de las causas que impiden la consolidación de viviendas.

Finalmente Ledgard (2015) y Gómez (1989) hablan de la experiencia de la UCV Huaycán (Unidad Comunal de Vivienda Huaycán) formado a través del equipo técnico de Izquierda Unida y la idea del arquitecto Eduardo Figari, nace en 1984 con el auspicio de la Municipalidad de Lima para solucionar el problema de la vivienda. Aparte Ledgard habla de su vivencia en 1985 en las incontables asambleas donde se constata y debate las decisiones de la UCV.

La UCV está conformada por sesenta familias organizadas de manera democrática, que ocupan menos de una hectárea, donde sesenta viviendas se distribuyen sobre las bases del espacio público. Ledgard menciona que los sesenta miembros de la UPIS son propietarios individuales de sus respectivos lotes $\mathrm{y}$, al 
mismo tiempo, propietarios colectivos de toda el área mancomunada (calles, plazas, áreas verdes, local comunal, servicios). La propiedad de lotes individuales es relativizada por el rol de la propiedad colectiva en la habilitación urbana.

Es así como luego de la descripción de la CUAVES, MIADES, UPIS Huáscar y UCV Huaycán confirmamos el concepto de autogestión propuesto y ahora tenemos el caso de la Asociación de Pobladores del sector «El Brillante», otra CUA ubicada en el distrito de San Juan de Miraflores y con la que hemos trabajado durante un proceso de 4 meses para la elaboración del presente artículo, las fuentes de información para este fueron entrevistas a dirigentes y pobladores del lugar, así como la revisión de los documentos del concurso de la historia de la comunidad en el 2006. El propósito fue tener una amplia perspectiva de su experiencia y un acercamiento directo para tener una mejor percepción y recojo de evidencia que nos permitiera conocer su situación pasada, presente y futura.

La Comunidad Autogestionaria de «El Brillante» fundada en 1966 en la zona de Pamplona Alta, en el distrito de San Juan de Miraflores, el trabajo está dividido primero en la historia de la comunidad El Brillante para hablar de todo el proceso que han pasado dentro de su organización vecinal; segundo identifica las relaciones internas donde veremos la estructura orgánica y funciones que asumen los programas de la asociación en la actualidad; tercero, analiza las relaciones externas para analizar las alianzas que han formado luego del cierre la cochera en 2015; y finalmente, presenta sus perspectivas de futuro.

\section{Memoria del sector El Brillante: 1967-2017}

\subsection{Antecedentes históricos}

Durante la década de 1950 se realizaron dos tomas de tierras importantes en la capital: la de Ciudad de Dios el 24 de diciembre de 1954 y la de Comas, Lima Norte, en 1956.

Ante estos acontecimientos, el Arq. Fernando Belaunde Terry, en su primer período como presidente del Perú (1963-1968) promulga la Ley Nº 13517. Ley de Barrios Marginales, exonerándolos de una serie de tributos a estos nacientes asentamientos huma- nos. Uno de estos seria la zona de Pamplona Alta que comparte el distrito de San Juan de Miraflores y Villa El Salvador.

Los inicios de los primeros pobladores de Pamplona Alta se remontan a un acto inédito en la zona conocida como Tacora. En el año de 1963, siendo el alcalde de Lima el Dr. Luis Bedoya Reyes, se decide unir la Av. Aviación con la Av. Grau. El único obstáculo para realizar este proyecto eran los habitantes de Tacora, pero luego del incendio en el lugar, el alcalde continuo con su obra.

La llegada de los primeros pobladores a Pamplona Alta se dio, como indica Díaz (2006), hacia enero de 1964 se trataba sobre la reubicación de pobladores de Ciudad de Dios, al no haber algo concreto, estos deciden invadir los arenales del Cerro San Francisco de la Cruz, llevando a cabo este hecho el 5 de enero de 1965.

El Brillante no fue una toma de tierras, sino un efecto y causa de ella, al iniciarse la lotización de San Francisco de la Cruz en octubre de 1966. En vista que el área de habitantes de San Francisco, no era suficiente para albergar a todos los posesionarios, la Junta de la Vivienda, en coordinación con la Junta Directiva, decide lotizar para los excedentes de la zona llamada la «chanchería» (Los Buenos Milagros).

\subsection{Fundación de «El Brillante»}

La Comunidad urbana autogestionaria «El Brillante» nace el 28 de enero de 1967 en las faldas del cerro San Francisco de la Cruz con los pobladores de las ocho manzanas, en la calle comprendida entre las manzanas 96-97. Este inicio se marca a través de una «Asamblea de Fundación» realizada por los pobladores de las ocho manzanas y el Instituto de Desarrollo Humano. Desde ese día histórico se celebra el Aniversario de la comunidad El Brillante por ser el día en el cual los habitantes de este nuevo sector decidieron separarse social y administrativamente de San Francisco.

Al fundarse el sector Brillante, no tenía este nombre. Comenzó trabajando con la denominación de la Mz 91 al 98, hasta el mes de agosto de 1967, mes en que se llevó a cabo una Asamblea General para definir la elección del nombre oficial. A través de la Asamblea General se hicieron 16 propuestas en don- 
de quedaron en empate dos propuestas de nombre: San Judas Tadeo y El Brillante.

Por San Judas Tadeo, el Sr. Julio Monrroy y Claude mantiene la propuesta expresando: «Somos un pueblo profundamente católico y San Judas Tadeo va a ayudarnos en este largo trajinar».

Por la denominación El Brillante, el Presidente Paulino Sedano Yupanqui defiende este nombre: «He propuesto este nombre como joyero que soy, el diamante en bruto no vale ni llama la atención de nadie, mientras no ha sido facetado y convertido en el Brillante. Es cuando se convierte en una joya admirada y codiciada por todos. Nuestra comunidad es como un diamante en ruto, recién está organizada y deseo darle las facetas, con nuestra unión, nuestro trabajo, nuestra organización y deseo de superación, para convertirla en una verdadera en un "Brillante», que resplandezca cual astro rey en el firmamento, y que sea luz y guía para todo, un ejemplar a seguir.»

Es así como ante esta magistral fundamentación, la denominación inicial "Mz. 91 al 98» pasó a ser remplazada por el seudónimo de «El Brillante».

Los socios desde entonces se organizaron a través de juntas directivas, siendo su primer Presidente el Sr. Paulino Senado el cual encabezo la primera Junta Directiva conformada por 6 miembros.

Cada manzana tuvo un representante, siendo en total ocho, por representante se conformaba a su vez una junta de 5 miembros. Sus reuniones se realizaban en el actual terreno del Teatrín Comunal.

Con la fundación de «El Brillante» sin un apoyo notorio por parte del Estado peruano, los pobladores optaron por hacerla una comunidad que sepa valerse por sí misma, donde todo lo que produzca, sea consumida por sus pobladores en formas de bienes y servicios. Así es como se constituyó como una comunidad urbana autogestionaria. Para ello, necesito primero, de una fuente de ingresos.

Si bien es cierto la comunidad de El Brillante desde su fundación en enero de 1967 hasta el año de 1998, no cobró ni obligó a pagar ninguna cuota de asociado a sus miembros para realizar sus gastos de gestiones institucionales, lo cual se consideró un error grave la no aportación de ninguna cuota para algo que se estaba obligado hacer como asociado. Los fondos para sus diversas gestiones fueron agenciados mediante actividades de: bailes sociales, reinados y donaciones, etc.
Entonces, en el año de 1999 se empieza a gestionar los ingresos para la comunidad mediante La Cochera, ubicada en el terreno del local comunal construido en ese mismo año. Fue la principal fuente de ingresos por muchos años en El Brillante, aquel que con el paso del tiempo dio fruto a la implementación y mejoramiento de varios servicios entre ellos el de la Biblioteca comunal o el Teatrín. La Biblioteca Comunal del Brillante, se funda como fuente generadora de educación, cultural y conocimiento; y a través de la Asociación Cultural de Jóvenes "Manuel Gonzales Prada» se firma un convenio con la Biblioteca Nacional adquiriendo un préstamo de 150 volúmenes de obras. Es de este modo como la biblioteca del Brillante comienza a funcionar con 150 volúmenes de libros, adicionalmente sumando a ello los prestamos conseguidos.

Sin embargo, la cochera genero mucha controversia dado las denuncias de los pobladores hacia las directivas administradoras por lucrar con los ingresos generados por ella. Y por si fuera poco, en el año 2011 entro en un proceso de litigio. Esto se dio precisamente por la dudosa administración de los bienes generados por parte de la cochera en anteriores Juntas Directivas. Por ello, la Superintendencia de Bienes Nacionales (SBN) había presentado una demanda por el manejo irregular de las anteriores directivas y esperaba hacerse del terreno de la cochera, para luego hacer una especie de subasta y venderla al mejor postor.

Ante esta situación, la solución más próxima era la de aceptar la condición por parte del Estado para no expropiarles el terreno de la cochera: usar dicho terreno para el funcionamiento de programas sociales, las cuales estarían apoyadas y financiadas por el Estado u ONG. Condición que fue aceptada. Entonces, desde el año 2015 el terreno de la cochera ya no estuvo más en subasta y se le otorgó la concesión del terreno a la comunidad por 10 años desde el año 2016. A propósito de esto, la presidenta de la Asociación, Linee Cáceres, dijo lo siguiente:

Por errores humanos en el año 2011 Bienes Nacionales expropia a la asociación porque se estaban llevando a cabo con actividades que no iban de acorde con la legislación que se le exige para el uso de un Local Comunal. Y eso ¡OJO! Es un punto que ahorita es el talón de Aquiles de muchos 
sectores de diferentes zonas. Hoy en día, terminando el período de Alan García, Bienes Nacionales toma el cargo de todos los Locales Comunales, es decir todos los terrenos del estado y exige que no seamos previos por la cual se vendan usufructos. Que sean Locales Comunales para servicios sociales. Entonces a raíz de eso se convoca una marcha para poder recuperar, pero ya con una nueva visón. Y ahí es donde viene lo de los servicios sociales, $100 \%$ servicio social, sin fines de lucro; entonces los ingresos que llegan a este Local Comunal, no son pues ingresos mancomunados como antes, antes era utilizado como cochera y era un dineral todo esto».

La historia de El Brillante tiene un contexto similar, respecto a su fundación, al de otros asentamientos humanos, pero también con un toque propio: el de valerse por la fuerza de sus pobladores para hacerse de un lugar donde vivir. Quizá sea por este espíritu autónomo, libre sin depender de la ayuda del Estado o del gobierno local que sus primeros pobladores tengan presente y se consideren muchos de ellos y sus descendientes como una comunidad urbana autogestionaria, la cual valoran mucho desde sus inicios y sea su principal carta de presentación ante la sociedad en general. Por ello también podría entenderse que muchos de estos primeros pobladores no acepten como se está manejando actualmente la comunidad por la Junta Directiva actual, pues consideran que este modelo de autogestión actual va contra el que ellos instauraron desde la fundación de la comunidad. Sobre este tema ya se profundizara más adelante.

\section{Relaciones internas}

El Brillante posee una nueva etapa de gestión a partir del 2015, por la segunda generación de los miembros de la junta directiva, ellos son los hijos de los fundadores de la comunidad. Esta etapa vive un cambio importante, de una política fijada en la redistribución de los recursos obtenidos por la cochera, a otra centrada en el modelo de proyectos sociales, entre los que involucra: el comedor, la biblioteca o el teatrín, la loza deportiva, los baños públicos, así como los programas del adulto mayor, kalli warma, incitec (dentro de la biblioteca) y el vaso de leche.
Las relaciones internas, hoy en día, tienen un carácter de índole social. Los representantes de la junta directiva son escogidos cada dos años. El Brillante tiene 450 socios, los jóvenes de la tercera generación tienen voz; pero no voto dentro de las decisiones directivas.

Para empezar esta parte, vamos a especificar primero la organización de «El Brilante», luego explicaremos los servicios autogestionarios y por último, las diferencias con el programa ayuda mutua.

\subsection{Organización de El Brillante}

El Brillante, como anteriormente indicamos, se encuentra ubicada en el distrito de San Juan de Miraflores, al sur de la ciudad de Lima, de acuerdo al plano trazado de la zona de Pamplona Alta, registrado con el código PO3050535, del Registro Predial Urbano, la estructura orgánica se encuentra dividido por tres entes principales: La Asamblea General (máxima autoridad conformada por 450 socios), coordinadores (20 personas encargadas de las calles y su coordinación con la Junta Directiva) y La Junta directiva (tiene 10 responsables de trabajo: Presidente, Vicepresidente, secretario de actas, secretario de tesorería, secretaria de organizaciones, secretaria de defensa, secretaria de deportes, asistenta social y dos vocales ${ }^{2}$ ).

Los miembros de la Junta Directiva tienen dos tipos de reuniones: ordinarias y extraordinarias. $\mathrm{La}$ primera son aquellas realizadas los días miércoles a las 8 de la noche y las extraordinarias son aquellas que se dan al momento de tomar decisiones de carácter de urgencia. Con la participación y organización de la junta se llegó a constituir instituciones comunales como: La Biblioteca Comunal el Brillante y el Comedor Autogestionario.

Como fondo de ingreso para sus inversiones y reinversiones en la comunidad se llegó a aprovechar el uso de «La Cochera». Este espacio fue un beneficio para la población del Brillante hasta el año 2014, ya que cubrió a su vez gastos realizados por los pobladores como el consumo de energía, agua, gas, pago a algunos trabajadores contratados dentro de la junta vecinal, etc.

2 Los vocales son aquellos con capacidad de reemplazo, es decir son aquellos que sustituyen a cualquier miembro de la Junta cuando se ausentan, ya sea por motivos de salud, personal y demás. 
Posteriormente, con la intervención de la entidad de Bienes Nacionales en la cochera se solicita a la Junta Directiva que se cumpla con los Programas Sociales que el estado exigía para que pueda seguir en funcionamiento el espacio de la cochera, ya que de no ser así la propiedad sería incluida dentro de una subasta pública a la venta.

La Comunidad Autogestionaria «El Brillante» ha logrado valerse por sí misma a través de un desarrollo social y económico. Observamos un desarrollo social a razón de la creación de distintas instituciones en las cuales cada ente tiene diferentes objetivos. La Biblioteca Comunal el Brillante se encuentra conformada por dos ambientes: La biblioteca y el teatrín, donde se desarrollan talleres como: karate, teatro y danza. En estos espacios se benefician, jóvenes, niños y adultos, este grupo último es partícipe del «Taller Adulto Mayor» y; por otro lado, se encuentra el Comedor Autogestionario sustentado por los propios comuneros con sus propios recursos. Generalmente el consumo se encuentra valorizado en 5.00 soles, este cobro es una excepción para las personas con extrema pobreza, esta situación económica es evaluada por los mismos comuneros, a través de la Asistenta Social. Finalmente, el uso de la Loza deportiva que a pesar de ser de uso libre y gratuito como parte de la gestión municipal, la población (en conjunto) decidió proveer de iluminación al campo y a partir de ahí administrar el uso de las luces de este espacio. El uso de las luces que los pobladores ofrecen tiene un costo el cual es un ingreso económico para la Comunidad Autogestionaria el Brillante.

\subsection{Servicios autogestionarios}

Se reconoce en la actualidad que la comunidad de El Brillante cuenta con dos tipos de servicios, puesto que la cochera dejó de funcionar a partir de la intervención de la entidad de Bienes Nacionales. En primer lugar se reconoce los proyectos sociales brindados por medio de la administración y convenios con entidades públicas y privadas. En segundo lugar están los servicios autogestionarios, es decir esos servicios que aún se conservan para mantener ingresos en la comunidad.

Debemos dejar en claro, una vez más, que la cochera se concibe como un bien nacional, si no se cumple con los programas sociales que el Estado exige, este subastará el terreno; por esa razón es que actualmente su alquiler se ha visto detenido por la gestión actual de la comunidad de El Brillante. Pese a ello han sabido mantener otros tipos de ingresos. Que como ya señalamos, estos servicios son el alquiler de luces, el servicio del comedor y el alquiler de baños.

En la loza deportiva se han instalado iluminación por la cual se cobra un alquiler de 20 soles por hora, no se cobra por el uso de la loza, entendamos que este es libre para cualquier miembro de la comunidad, pero en el caso se necesite usar la iluminación se efectúa el cobro del mismo.

Existen partidos diariamente que incluso se apuestan dinero, como nos comentó un vendedor de comida ambulante. Los partidos son regularmente ocupados por jóvenes a partir de las 4 de la tarde y se mantienen entre dos o tres partidos. En este mismo lugar se maneja parte del programa "Yachay» del Ministerio de la Mujer y Poblaciones Vulnerables.

A pesar de la tranquilidad del lugar, un poblador comenta que personas «indeseables» tienen la costumbre de ir ponerse allí para fumar o ingerir droga durante altas horas de la noche. Se ha pedido apoyo al municipio, pero poco o nada han logrado, así que se han mantenido de forma autónoma para enfrentar ello, lo que ha producido — según comenta - una disminución de ese tipo de hábitos.

Otro servicio, aunque no produce ganancias exuberantes por su carácter social, es El Comedor donde con los recursos que se tiene se logra preparar los alimentos del día para luego ser vendida a un precio simbólico de 5 soles, de este modo cualquier persona que desee, puede consumir solo pagando los costos de preparación. Estos menús son vendidos a través de tickets para que de ese modo se haga factible contabilizar las raciones vendidas y poder sacar, luego, un informe económico, el cual está a cargo del administrador. Este informe es rendido ante el Secretario de Economía de la Junta Directiva, quien tiene que verificar los costos y pedir informes consecutivos a la encargada del comedor, la señora Irma Centeno.

Fue el señor Eusebio Matos quien la invitó a trabajar en esto. Ella comentó «de joven no tuve interés en trabajar para la comunidad, prefería dedicarme a mis proyectos personales». Pero con el tiempo, ella vio como oportunidad el quedarse allí. Así nos comenta que los jóvenes no están muy involucrados en 
estos temas, ellos tienen más visión en otro tipo de actividades, sobre todo en el uso de internet. El servicio es mayormente usado por los pobladores adultos. El Comedor también ha visto una reducción en la distribución de sus raciones debido a la presencia de restaurantes cercanos. "Muchos de los que vienen al comedor son personas de las comunidades aledañas»... nos comentó la señora Irma.

El comedor comienza sus servicios a las once de la mañana y transmiten el menú a través de megáfonos instalados en la comunidad para que todos puedan estar informados y puedan acudir al comedor.

Por otro lado está el alquiler del baño, el cual representa un ingreso a partir de su uso por parte de los comerciantes informales y transeúntes que necesitan de este servicio. Se tiene un total de cuatro baños (dos de varones y dos de mujeres). Un caso aparte es el bańo creado para uso exclusivo del programa adulto mayor. El uso del servicio tiene un costo único de 50 céntimos, y está disponible al público hasta el cierre del local comunal.

\subsection{Diferencias con el programa ayuda mutua}

Como dijimos hay un antes y un después luego del cierre de la cochera, ahora se mantiene bajo un nuevo modelo administrativo el cual está íntimamente relacionado con los programas sociales y se ha separado del programa de ayuda mutua, el cual era un programa identitario para esta comunidad.

«Con la cochera El Brillante estaba mejor» - comento un socio de la comunidad-. Según algunos pobladores, era un momento donde se hacía entrega de canastas cada cierto tiempo y se llevaba, según ellos, un sistema donde el dinero era redistribuido a la comunidad. Ahora el proyecto está sustentado por otros medios que ya hemos señalado, el cual demanda mayor participación comunal. Otro poblador comentó «casi nadie asiste a esos proyectos, deberíamos volver al modelo anterior».

Se tenía fondos de la comunidad para ser usados en algún caso en donde algún miembro de la comunidad que haya sufrido algún accidente o problema de salud pueda atenderse y resolver su caso. «Estos fondos variaban de acuerdo a escalas: 300 soles si están enfermos, 500 soles en caso de hospitalización y 1100 soles por fallecimiento, que vale decir es heren- cia del modelo de la primera generación", comentó el Sr. Eusebio Matos.

«Pero existieron problemas con esos administradores» comentan otros entrevistados. Habían personas que asumían los cargos solo con la intención de enriquecerse "mira solamente las casas donde viven", comentó una pobladora; «la junta actual se diferencia de las anteriores, no tienen registrado un sueldo como lo tuvieron los anteriores, son más justos y se centran en lo que pide el gobierno, los gobiernos cambian y la fiscalización también, tenemos que adaptarnos y no cerrarnos en lo antiguo", comentó otra pobladora.

«La comunidad ha crecido de forma machista, hay discriminación hacia la actual presidenta por ser mujer» dijo el señor Ángel Odar, secretario de economía. «Desde la formación de «El Brillante» se ha pasado por presidentes masculinos, ella es la primera en asumir este cargo, ella es también la esposa del presidente anterior», dijo. La Junta actual comenta tener, como toda gestión, breves discordancias pero siempre llegan a tener un consenso.

«El último domingo de enero ellos tienen su fiesta de aniversario decoran las calles, tienen un magno evento e impiden el comercio ambulatorio» — dijo molesto un vendedor- «si quieren hacer su fiesta está bien pero por que tienen que perjudicar nuestro ingreso». Aunque admite también que hay ambulantes que son «indeseables», pues ni su lugar de trabajo puede mantener limpio.

Otra diferencia que podemos notar en el cambio de generación en la dirigencia, es con respecto al concepto que se le da al terreno de la cochera. El programa de ayuda mutua lo veía como una propiedad de la comunidad a diferencia que en la actualidad se concibe como propiedad del gobierno. Actualmente, la Junta está cumpliendo con los requisitos que les ha dado el estado y se ha cerrado el uso del terreno como cochera. Hecho que genera una gran molestia en los pobladores pertenecientes a la primera generación, quienes nos manifestaron que no debía ser así, «el estado nunca ha apoyado al brillante y nos hemos gestionado de forma independiente», manifestaron.

\section{Relaciones externas}

Las relaciones con su entorno se ha dado de manera débil, como se menciona en la historia de esta comu- 
nidad nunca se dio directamente una relación con algún organismo del Estado para desarrollarse, puesto que mediante la organización autogestionaria3 de los pobladores se realizó la intervención autónoma para la resolución de necesidades. La autogestión — según Germaná- es la máxima expresión de la organización vecinal, está a pesar de su autonomía, sigue involucrada con agentes externo, en esta parte veremos su relación político-institucional con el estado, las relaciones con otras comunidades y las relaciones con universidades y organizaciones públicas.

\subsection{Relación político-institucional con el estado}

El Brillante se vio olvidada por el Estado desde sus inicios, los básicos como el agua, alcantarillado y la pavimentación fueron gestionados por la Junta Directiva de la comunidad. El señor Matos, uno de los fundadores y ex-miembro de la Junta Directiva, menciona lo siguiente:

Nuestras pistas fueron hechas con nuestro propio dinero y hasta hoy ya tienen 25 ańos y aun sirven. La municipalidad siempre se ha mantenido al margen, nosotros organizados hemos ido logrando cosas. El Brillante no ha sido reconocido hasta ahora como una urbanización por ello no se pagan impuestos, pero hace poco el vecino de al lado construía su casa y un pequeńo local y la municipalidad lo quiso paralizar pero no pudo porque no somos una urbanización.

$\mathrm{Al}$ constituirse El Brillante, en sus inicios, como una comunidad autogestionaria su organización se basó en la figura de socios. Fomentando, de ese modo, el cooperativismo que les permitió desarrollarse. El financiamiento para la construcción de pistas que menciona el señor Matos, ex dirigente de la comunidad, se realizó mediante los ingresos percibidos por el alquiler de la cochera, con lo cual se generaron fondos para hacer frente a sus gastos principales. Es como lo menciona Humberto Ortiz en su libro sobre economías populares "La búsqueda de satisfacer necesidades en común hace que los pobladores se

3 Las prácticas de autonomía en la autogestión están íntimamente vinculadas a su capacidad de generar estrategias para sostenerse en el tiempo, en torno a lo cual existen una serie de posiciones y debates dentro del propio campo de la economía social y solidaria (Gracia, 2015) organicen y puedan autogobernarse y se produzca la autogestión».

Muy diferente al caso de Villa El Salvador, El Brillante como comunidad surgió mediante su propia organización interna y sus planes autogestionarios sin seguir un modelo propuesto por algún organismo estatal.

En la actualidad cuenta también con el programa del vaso de leche que tiene sus instalaciones en el local comunal. Este programa fue implementado en 1984, el cual subsiste bajo la organización de las madres de familia quienes pagan una cuota mensual de dos soles para obtener un tarro de leche semanal y avena (entendiendo que es una ración por hijo) .Estos alimentos son distribuidos por la municipalidad a cada comunidad y el comité de Vaso de Leche se encarga de repartirlo a cada madre de familia empadronada en el programa.

El Ministerio de Educación y la municipalidad desde hace cinco años también se hacen presente en la comunidad con el CEBA en beneficio del adulto mayor y el programa Yachay. El programa del adulto mayor recibe entre 25 a 30 personas quienes son guiados por la profesora Gladys Ángeles. Ella enseña a los adultos participantes diversos cursos, dividiendo la semana en diferentes talleres: lunes, miércoles y viernes educación básica, los días martes manualidades y finalmente los días jueves danza y terapia física. Las instalaciones para el CEBA se encuentran dentro del espacio correspondiente a la cochera, al culminar cada taller se realiza la venta de lonches cuya colaboración es voluntaria; esto con el fin de buscar solventar algunos gastos que tengan.

El programa Yachay impulsado por el Ministerio de la Mujer y Poblaciones Vulnerables se encuentra presente desde el 2014. En el distrito de San Juan de Miraflores no se cuenta con un local destinado a este programa, por lo que a partir de este año la Junta Directiva presta un espacio del local comunal para el desarrollo del programa (brindando servicios a cuatro sectores vulnerables: menores que trabajan, mendigan, sufren explotación sexual y hacen vida en la calle)

En ese sentido se evidencia un mayor acercamiento de la comunidad con el Estado en búsqueda de atención a problemas que se enfrentan y a necesidades que no pueden ser cubiertas por su propia autogestión, debido a la ausencia de financiamiento 
propio y debido, también a la expropiación de la cochera, que aunque se preste a distintos comentarios sobre su administración y en cómo se destinaba los ingresos generados, es un hecho real que lograba sustentar algunos servicios.

\subsection{Relaciones con otras comunidades}

En un inicio mantenían unas relaciones tenues con estas comunidades con reuniones para los problemas comunes. En la actualidad el caso es distinto, la presidente en turno de la comunidad El Brillante la señora Linee menciona:

«Es difícil ahora hacer acuerdos con las otras comunidades, pues están más preocupados por los aspectos políticos, se acerca las próximas elecciones municipales. Pero si hay la idea de poder conversar y afrontar problemas en común y compartir experiencias"

En ese sentido entendemos que la búsqueda de una mayor comunicación con los vecinos de otras comunidades se ve afectada por los distintos intereses que presentan cada comunidad, dejando de lado el sentido de comunidad y de cooperativismo. Aunque también es cierto que se trata de mantener cierto contacto.

\subsection{Relaciones con universidades y organizaciones publicas}

Los proyectos sociales son el curso de INCITEC que se brinda dentro de la biblioteca y el programa del adulto mayor sustentado a través de convenios realizados con la Universidad Alas Peruanas. Este convenio realizado hace algunos años consiste en que alumnos de esta universidad puedan realizar investigaciones y apoyar en el área de gerontología, favoreciendo así a los adultos mayores de la comunidad.

En cuanto al convenio actual con INCITEC, este consiste en brindar un curso de computación para los jóvenes y adultos, el cual representa una gran iniciativa pero que lamentablemente cuenta con pocos miembros.

Debemos señalar que estos proyectos son aquellos que ya están en vigencia, pero hay otros que están aún como proyecto, como es el caso de Qali Warma entre otros, este último se desarrollará con mayor precisión en el punto respecto a perspectivas a futuro.
En el presente la directiva de la comunidad El Brillante reconoce la necesidad de hacer conexiones y trabajar en conjunto con los programas sociales brindados por diferentes ministerios, esto en búsqueda de una mejora para la comunidad, tal como lo menciona la señora Linee Cáceres, «Es necesario poder trabajar en conjunto con estos programas sociales, para sí poder ir mejorando el Brillante y brindando oportunidades para que este lugar se desarrolle y cambie para bien.»

El deseo de entablar nuevos vínculos con el entorno está presente y se ha constituido como una necesidad para esta comunidad, debido a los nuevos problemas que afrontan, que tienen que ver con los problemas sociales que aquejan a Lima en general; y además por la falta de una alternativa que remplace la fuente de ingresos que generaba el alquiler de la cochera.

Entonces se puede decir si las relaciones con el entorno son tenues o tienen una organización hacia adentro, pues se tendrá que contra en lo primero, puesto que dentro de la nueva junta se ha intentado generar nuevos contactos, ya no solo por parte de lo público como principal, sino también con organizaciones privadas, pero salvo con el Grifo Primax, no hay relaciones de mutuo compromiso donde pueda darse un contacto más continuo y duradero, pero están nuevas posibilidades de búsqueda.

\section{Perspectiva a futuro}

Contempla la perspectiva propia de la Junta Directiva y de sus pobladores. Este se destaca en tres aspectos generales: Las fuentes de ingresos, los servicios que se brindan producto de estos ingresos para la comunidad, y la identificación por parte de la población en general respecto a si se consideran una comunidad autogestionaria. Esta clasificación de aspectos generales se realiza con el fin de mostrar el carácter de autogestión en la ciudad que pretende este estudio.

\subsection{Sobre las fuentes de ingresos}

Sin la cochera como principal fuente de ingresos, la pregunta a hacerse sería ¿Cómo obtener mayores fuentes de ingresos para continuar brindando servicios a la población? Ante este problema, la actual 
Junta Directiva (período 2017-2019), tiene planificada una serie de proyectos, como lo son la construcción de una capilla social, también existe el proyecto de hacer un campo de fulbito de grass sintético, además de seguir apoyándose con los ingresos actuales que les brindan el Comedor, los baños públicos, las luces de las actuales lozas deportivas, alquiler del teatrín y local del adulto mayor.

La capilla social junto al campo de grass reemplazaría los ingresos antes generados por el alquiler de la cochera, ya que ambos a través de sus ingresos, como lo señala la presidenta Linee Cáceres: «seguirán cumpliendo con el rol de autogestión en la comunidad brillantina. Deseamos concretar estos proyectos porque consideramos que de esta manera continuaremos teniendo fuentes de ingresos propios y así seguir brindando nuestros servicios a toda la población de El Brillante».

En cuanto a las actuales fuentes de ingresos como el comedor, es sabido que conforme pasan los ańos, disminuye la demanda de comensales y, por ende, disminuye los ingresos. Una de las causas es la competencia de negocios propios de restaurantes en la misma comunidad de El Brillante. Y esto parece ser una tendencia prolongada hacia el futuro.

Respecto a las otras fuentes de ingresos, en este caso, la loza deportiva y los baños públicos, estos siguen siendo fuentes de ingresos de regular demanda, en especial el de los bańos públicos, aunque no logra ser una considerable fuente de ingresos. Y las otras fuentes de ingresos restantes corresponden al alquiler del local del adulto mayor y el del teatrín, cuyo uso son cada vez más esporádicos, tendencia que deviene ya desde ańos anteriores.

Por ello, la actual Junta Directiva se esperanza en la realización de los proyectos de la capilla social y el del campo de grass sintético, considerando que les dará mayores ingresos para continuar brindando los actuales servicios u otros nuevos a la comunidad brillantina. No olvidar lo indispensable que se considera a las construcciones de los locales de funcionamiento de estos proyectos. Para ello se está buscando apoyo de ONG para el financiamiento de la infraestructura del proyecto de la capilla social. Y en cuanto a la realización del campo de grass sintético, la Junta actual cuenta con un perfil de proyecto, el cual fue elaborado por el señor César Quispe (independiente) quien además se perfila como posible candidato a la alcaldía del distrito de San Juan de Miraflores. Este además ofreció que en caso llegara a la alcaldía del distrito, se dispondrá el financiamiento para este proyecto.

\subsection{Sobre los servicios brindados}

Los servicios que se pretenden brindar en la comunidad urbana El Brillante están condicionados por parte del Estado ya que, para no expropiarse el terreno de la cochera, se debe implementar programas sociales.

En cuanto al programa social del Estado "Qali Warma», existe un deseo de poder implementarla con el fin de lograr un servicio de alimentación adecuada para un desarrollo educativo eficaz en los niños de la Asociación. El cual, según este programa, estaría dirigido a los niños y niñas matriculados en instituciones educativas públicas del nivel inicial y primario. Consideran muy importante la implementación de este proyecto en El Brillante ya que desean un mejor desarrollo humano para las futuras generaciones y consideran además que una política de alimentación que considere a los nińos de forma responsable, es sinónimo de desarrollo. Se considera la inmediata realización de este proyecto, ya que como se mencionó antes es parte de la condición puesta por el Estado para no expropiarse del terreno de la cochera.

Respecto a los servicios socioculturales actuales brindados para la comunidad general en El Brillante, salvo en los talleres de manualidades del adulto mayor, en la actualidad existe cierto déficit en cuanto a la participación de la «tercera generación» en El Brillante (que vendrían a ser los nietos de los fundadores). Para el Secretario de Economía, Ángel Odar, esto se debe a que «los jóvenes no lo ven como algo productivo a futuro». En la actualidad, existen como mínimo solo cinco integrantes y máximo 10 , que pertenecen a los talleres desarrollados en el teatrín. Y todos ellos son de sectores externos a El Brillante (San Gabriel, Pamplona Alta). Nos comentaba también Eusebio Matos Flores, uno de los fundadores del Sector El Brillante, que «la ausencia de los jóvenes ante el interés por hacer uso de estos servicios se da ante la influencia del desarrollo tecnológico del cual forma parte esta tercera generación", puesto que de alguna manera se sienten más atraídos a este fenómeno tecnológico moderno y descuida el interés hacia aspectos socioculturales que se encuentran en los servicios que brinda la comunidad. 
La preocupación se centraría en cómo se puede contrarrestar la trascendencia de este desinterés en las futuras generaciones. Ante ello, la Presidenta Linee Cáceres junto a su Junta Directiva implementó algunos nuevos programas como es el taller de cajón criollo para niños. Esto con el fin de incentivar a padres y madres de familia (principalmente a las madres) para poder implementar programas como repostería, cocina, entre otros. Se considera como una buena estrategia ya que así muestran a los padres y madres que se están haciendo programas importantes para el desarrollo humano de sus niños y de paso incentivarlos a ellos mismo.

En cuanto a los jóvenes, que son el principal sector de la población desinteresada por estos servicios brindados, la Junta Directiva implementó el taller de boxeo, a partir del cual se observa cierto incremento del interés por parte de la juventud brillantina. Este programa se implementó con la idea de que a la juventud hoy en día, le interesan más lo deportes, en especial los que liberan la tensión y el estrés. Además de inculcar valores del espíritu deportivo, competitivo y cultural de este deporte.

Aunque ya se está haciendo algo para mejorar el interés de quienes constituyen la tercera generación de El Brillante hacia los servicios que se brindan, aun no parece ser suficiente. La Junta Directiva, al igual que la población en general, ha propuesto algunos incentivos que logren despertar el interés en la juventud, es lo que se buscaría para cambiar este panorama poco alentador en la actualidad. Ya que de seguir así no tendría sentido el esfuerzo que se está realizando por parte de las fuentes de ingresos para, precisamente, financiar los servicios que brinda la comunidad urbana El Brillante para sus pobladores en general, principalmente pensando en el futuro de su tercera generación y próximas generaciones. Además, que de esta manera no se estaría completando un modelo autogestionario en la ciudad, pues solo funcionaria la parte de las fuentes generadoras de ingresos y no el aprovechamiento de los servicios brindados financiados por los primeros.

\subsection{Sobre la identidad de la población en general res- pecto a la autogestión en la ciudad}

En este punto, se encontraran opiniones diversas de algunos pobladores de la comunidad urbana auto- gestionaria El Brillante, consultadas respecto a sus perspectivas a futuro del modelo de autogestión en su comunidad. Esto con el fin de poder acercarnos a nuestro problema planteado sobre si aún debería estar vigente el modelo de autogestión en la comunidad urbana El Brillante.

En cuanto a la opinión de la Junta Directiva, la Presidenta Linee Cáceres nos dice que «aún consideramos que se trata de una autogestión, porque si bien es cierto se perdió la cochera que era la principal fuente de ingreso de la comunidad, todavía tenemos el comedor, las luces de las losas deportivas, el alquiler del teatrín, entre otros más, así como los nuevos proyectos como la capilla social y el campo deportivo de grass sintético. Mi junta y yo aún consideramos que seguimos por el camino de autogestión comunitaria que hemos heredado desde la fundación del sector El Brillante, camino que seguiremos manteniendo con miras al futuro». Esta opinión, según la Presidenta, es compartida por la mayoría de la población, en especial las mujeres adultas mayores, a pesar de la pérdida del alquiler de la cochera y la implementación de programas sociales del Estado, que era la opción más inmediata para no perder el terreno de la cochera, aceptada por la Junta Directiva anterior y seguida por la actual; la cual, dicho sea de paso, cuenta con algunos miembros reelegidos.

Otra opinión recogida es de Irma Centeno, administradora del comedor. Ella dice que «todavía existe unión, solidaridad en los pobladores. Todavía se siguen aprovechando los servicios que brindan la comunidad». Esto podría reflejarse, en el caso del comedor, en los adultos mayores que son los mayores consumidores, muchos de ellos fundadores. Sin embargo, es real que parte de estos consumidores son personas externas al Brillante. Agregando a esto, la tendencia de bajos ingresos en promedio por ańo y la competencia de restaurantes en la comunidad, se puede deducir que a futuro, a menos se aplique alguna política que incentive la demanda del uso del comedor, estos valores de unión y solidaridad como muestras de apoyo por parte de la población, en especial la segunda, tercera y próximas generaciones, seguirá disminuyendo tal como señala esta tendencia.

Sin embargo, existen también opiniones distintas a la de la Junta Directiva. La mayoría son de la primera generación, principalmente de los que fueron los fundadores del sector. Uno de ellos es el Sr Eusebio 
Matos Flores, quien cree que «se ha perdido la esencia del Brillante: el de la comunidad autogestionaria de sus propios recursos para brindar los servicios a su pueblo». Por ello, él al igual que otros pobladores, durante la situación en donde la Cochera estuvo en litigio, sugirió una salida a futuro de carácter legislativa. Esta consistía en la presentación de un Decreto Ley ante el Congreso de La Republica. El cual estaría encargado de establecer que los locales comunales serian propiedad de los pueblos; logrando, así, la recuperación del terreno de la cochera para su alquiler, considerada como la principal fuente histórica de ingresos para satisfacer autogestionariamente las necesidades de la población.

Es decir, se negaban rotundamente a perder la administración del uso del terreno de la cochera para alquiler, situación que en la actualidad ya no es usada más para ello. Precisamente esto nos evidencia que este sector de la población, entre ellos el Sr. Eusebio Matos, es oposición a la Junta Directiva, pues consideran que han traicionado al modelo de autogestión que ellos implementaron desde la fundación de la comunidad urbana El Brillante, con la pérdida del alquiler de la cochera y con ella su principal fuente de ingresos. Y esto podría atentar, quizá, más adelante con el modelo de autogestión socioeconómico aplicado en esta comunidad, llegando al punto de renunciar a este modelo.

Otra opinión es de Marta Allosa, vendedora ambulante y pobladora de El Brillante, al ser consultada sobre su opinión sobre el futuro de la autogestión en su comunidad, nos dijo que «los dirigentes solo se dedican a lucrar, se aprovechan de los ingresos que tienen de la cochera, comedor, etc.» $\mathrm{A}$ partir del cual se puede dejar entrever que existieron ciertas condiciones durante la administración de la comunidad, ciertos manejos de los recursos y se desprendieron algunos beneficios que dejaba fuera a algunos pobladores. Hecho que generó que se acreciente la desconfianza de los pobladores hacia sus dirigentes y trajo, además, la intervención del Estado y sus instituciones.

Ante estas distintas opiniones se puede ver que las medidas hechas por la Junta Directiva anterior y la actual (medidas hechas con apoyo del Estado), ante este llamado renovado modelo de autogestión de la ciudad, son supuestamente aceptadas por la mayoría (no es aceptada por un sector reducido), de la población brillantina. Otros aún tienen la mala imagen de las anteriores directivas y no creen en el trabajo de la Junta Directiva actual. Sin embargo, esto se puede interpretar que se siguen identificando como un modelo de autogestión comunitaria urbana, solo que con algunos cambios o reformas. Modelo que, según sus dirigentes, pretende seguir trascendiendo, con el fin de que el Brillante siga siendo vista como una comunidad ejemplar en el distrito, la capital y el país.

\section{Conclusiones}

La autogestión de la ciudad está en vigencia desde la búsqueda de vivienda, ha tenido diversas formas de organización social, política y económica; pero que también se centra en solucionar los problemas internos de su sector. Si bien se presenta como una alternativa que escapa a las formas de organización actual, la autogestión aún se mantiene como propuesta.

En ese sentido, la comunidad de El Brillante ha sufrido un cambio en su constitución a través de su desarrollo, cambios de forma y fondo que no solo tienen que ver con el recambio generacional en su dirigencia sino que también con los propios mecanismos que emplean para captar recursos.

La comunidad ve alterada en su constitución autogestionaria llevándolo en 1998 a la denominación legal de asociación de pobladores. El Brillante representa aún un modelo de autogestión de la ciudad y es un precedente claro de lo que constituye una economía de tipo social, aunque se haga casi imposible negar el hecho de que este corre el riesgo de desaparecer por completo, ya que en la actualidad atraviesa una crisis.

Es a partir de ello que podemos evidenciar algunos puntos claves mediante el cual se hacen manifiestos los cambios en las características de la comunidad. El primero de ellos tiene que ver con la generación de recursos, el cual como ya hemos señalado, ocasionó un cambio drástico en la administración de la comunidad, afectando no solo a los recursos que ingresaban sino también a los servicios que se ofrecían, y trajo también discrepancias entre un sector de la población que se identifican como los fundadores de El Brillante, y otro sector que surge como una nueva 
generación y que se constituye como la nueva imagen de la comunidad.

Discrepancias que ocasionaron que la población se aleje y deje de participar en la gestión comunal. Esto último puede deberse a la falta de confianza hacia los dirigentes o hacia la figura del dirigente; así también se debe a la pérdida de un incentivo que la población antes encontraba y que hacía más llamativa su presencia en la misma gestión comunal.

Otro cambio importante se vincula a la identificación del poblador con su comunidad. Evidenciamos que la población de la comunidad El Brillante manifiesta claras diferencias con respecto a su pertenencia pese a ser todos parte de ella. Hoy en día existen 2 sectores, unos se denominan «brillantinos» mientras que otro sector se hace denominar «hijos de El Brillante». Estas diferencias no solo son respecto a su visión sino que responde también a una diferencia física en el terreno de la comunidad.

En el sector denominado «brillantinos» se aprecia una carga fuerte de identificación con lo que constituye la historia de El Brillante, especialmente, por los fundadores de la comunidad; estos se sienten orgullosos de lo que fueron y se podría decir que hasta de lo que son ahora, aunque algunos especifican que les gustaría regresar al modelo de gestión anterior. Mientas que en el otro sector se aprecia una indiferencia y falta de conocimiento con respecto a las labores que la comunidad realiza a través de la Junta Directiva. Algunos de ellos nos mencionaron que no tienen necesidad de participar en los servicios que presta El Brillante o que no tienen el tiempo suficiente como para asistir a las asambleas o reuniones.

A partir de esto podemos mencionar que no se ha logrado heredar esa identificación para con la comunidad en los jóvenes y falta constituir un verdadero cambio generacional, puesto que ese cambio representa un peligro para la pérdida total de la noción de pertenencia como comunidad, si es que no se logra emplear mecanismos capaces que contrarresten este fenómeno. Reto que queda para la actual Junta Directiva y las futuras que la sucedan. Situación de la que es consciente la actual directiva y de ahí la importancia que tiene impulsar proyectos que permitan atraer a la población joven y también a la adulta que ha perdido interés en participar.
Lo evidenciado en nuestra investigación nos permite entender las dificultades que presenta cualquier esfuerzo organizado por superar los problemas de una determinada población y las limitaciones que pueden tener los mecanismos que emplean para sustentar sus necesidades.

Es clara la importancia que tiene la propia comunidad y la labor que debe tener para su propio desarrollo. La generación actual de recursos económicos por el sistema capitalista no logra satisfacer por completo a la población que ve muy alejada su capacidad de desarrollo, por lo que se ve en la necesidad de generar sus propios recursos y empieza a organizarse o auto-organizarse.

\section{Bibliografía}

ARIAs, T. (2012). Uso, apropiación e inversión en espacios públicos urbanos de barrios populares caso de estudio: UPIS Huascar - San Juan de Lurigancho (Tesis de Maestría). Lima: UNI.

Becerra, M. (2017). Politicas vecinales en Villa el salvador: caso de los grupos residenciales del sexto sector de VES (2010 -2015) (Tesis de maestría). Lima: PUCP.

Calderón, J. (2016). La ciudad ilegal. Lima en el siglo XX. Lima: Punto Cardinal.

Coronado, J., \& Pajuelo, R. (1996). Villa el Salvador: poder y comunidad. Lima: CECOSAM-CEIS.

Fajardo, J. (2009). Organización y participación politica en el Perú, antes y durante el gobierno de Juan Velasco Alvarado. Lima: Editorial Universitaria Ricardo Palma.

Germaná, C. (1994). Algunas hipótesis sobre el autogobierno de las «Comunidades Urbanas» en el Perú. En Revista de Sociología. Número 9. Lima: UNMSM.

Gómez, M. (2008). Lineamientos para el desarrollo del dstrito de El Agustino (Tesis de pregrado). Lima: UNI.

Gómez, R. (1989). Autogobierno local: La experiencia de Huaycán. En Autogestión y autogobierno en el Perú: creación popular de la sociedad (pp. 31-36). Lima: Instituto Democracia y Socialismo.

Gracia, M. (2015). Indagar de posibilidades de las experiencias de trabajo asociativo autogestionario. En M. Gracia, Trabajo, reciprocidad y re-produccion de la vida. Experiencias colectivas de la autogestion y economía solidaria en America Latina (pp. 17-56). Buenos Aires: Miño y Dávila Editores. 
LEDGard, R. (2015). La ciudad moderna. Textos sobre arquitectura moderna. Lima: PUCP.

Meneses, M. (1998). La utopía urbana El movimiento de pobladores en el Perú. Lima: Brandon Enterprises.
Romero, F. (1993). Municipalidades y pobladores: el caso de la Miades en El Agustino. Lima: Servicios Educativos El Agustino.

\section{ANEXOS}

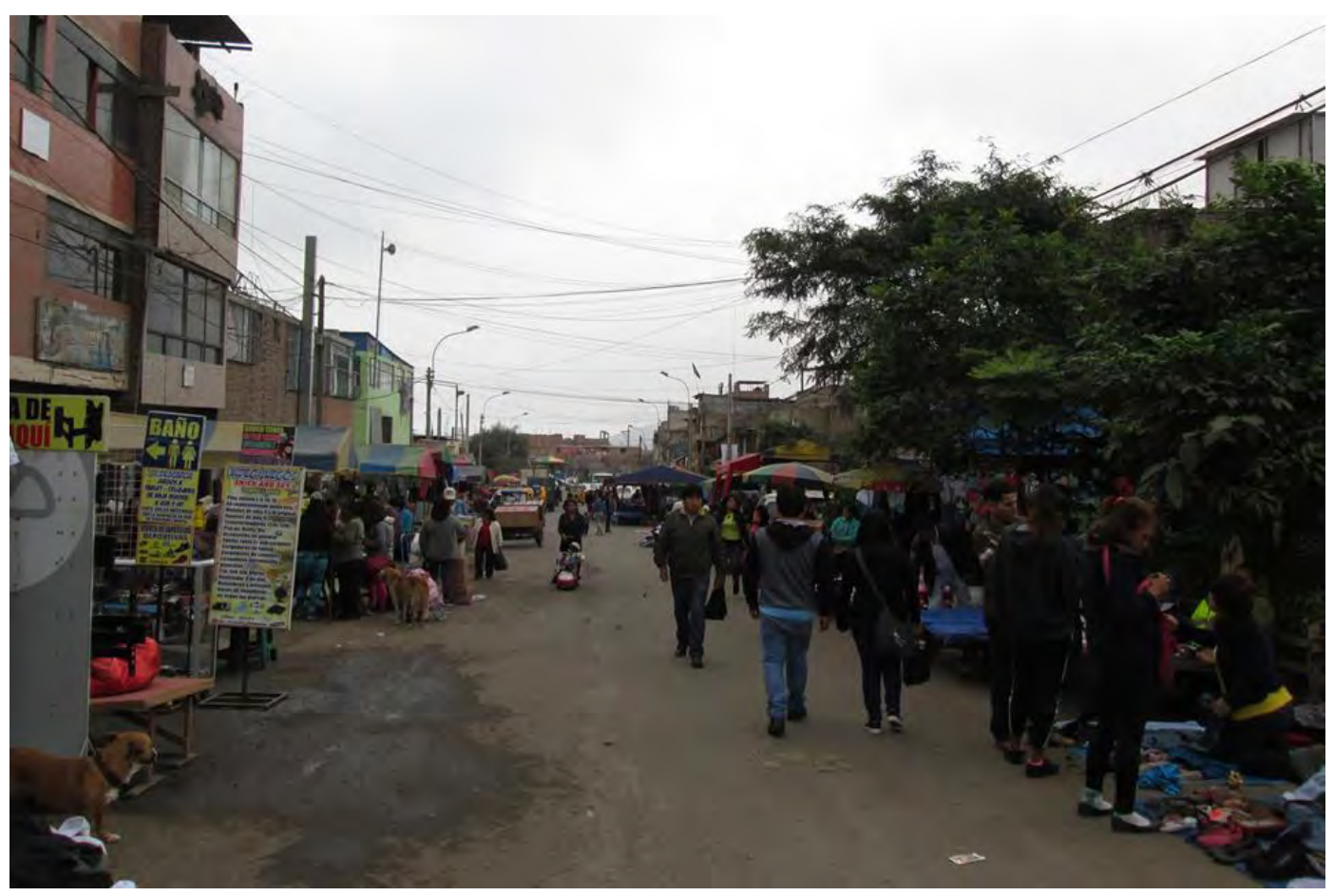

FOTо 1:

Ingreso a la

Comunidad El

Brillante.

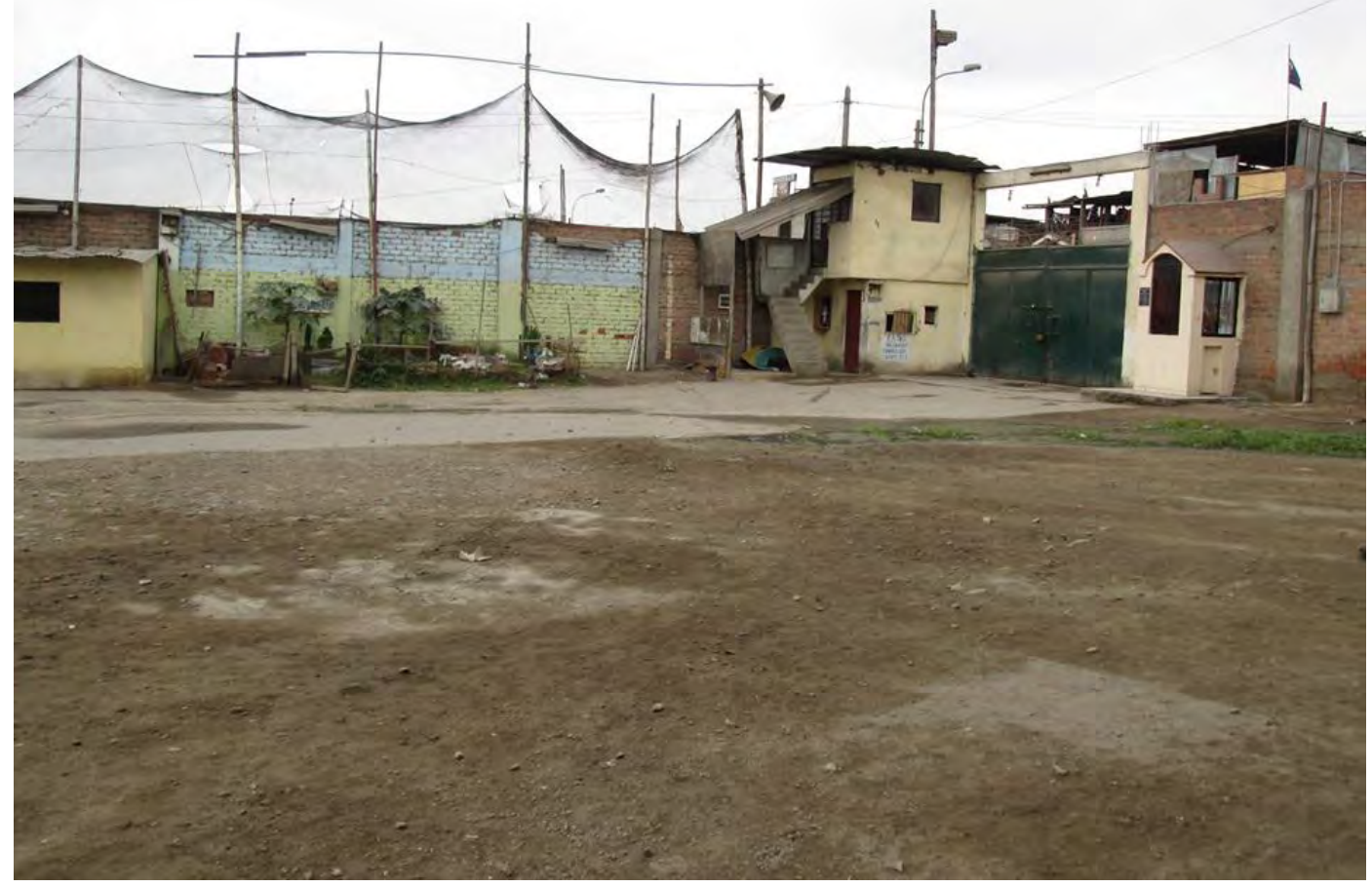

FОто 2:

Espacio que era destinado al alquiler de la cochera. 


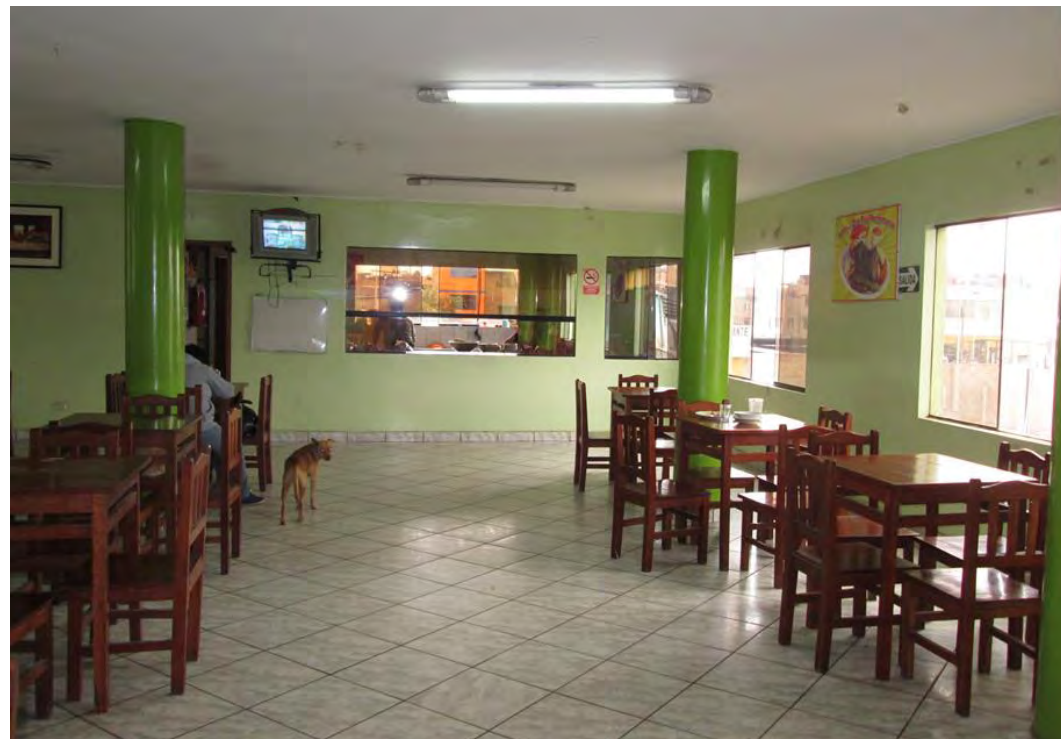

FOTO 3:

Local destinado al

servicio del comedor autogestionario

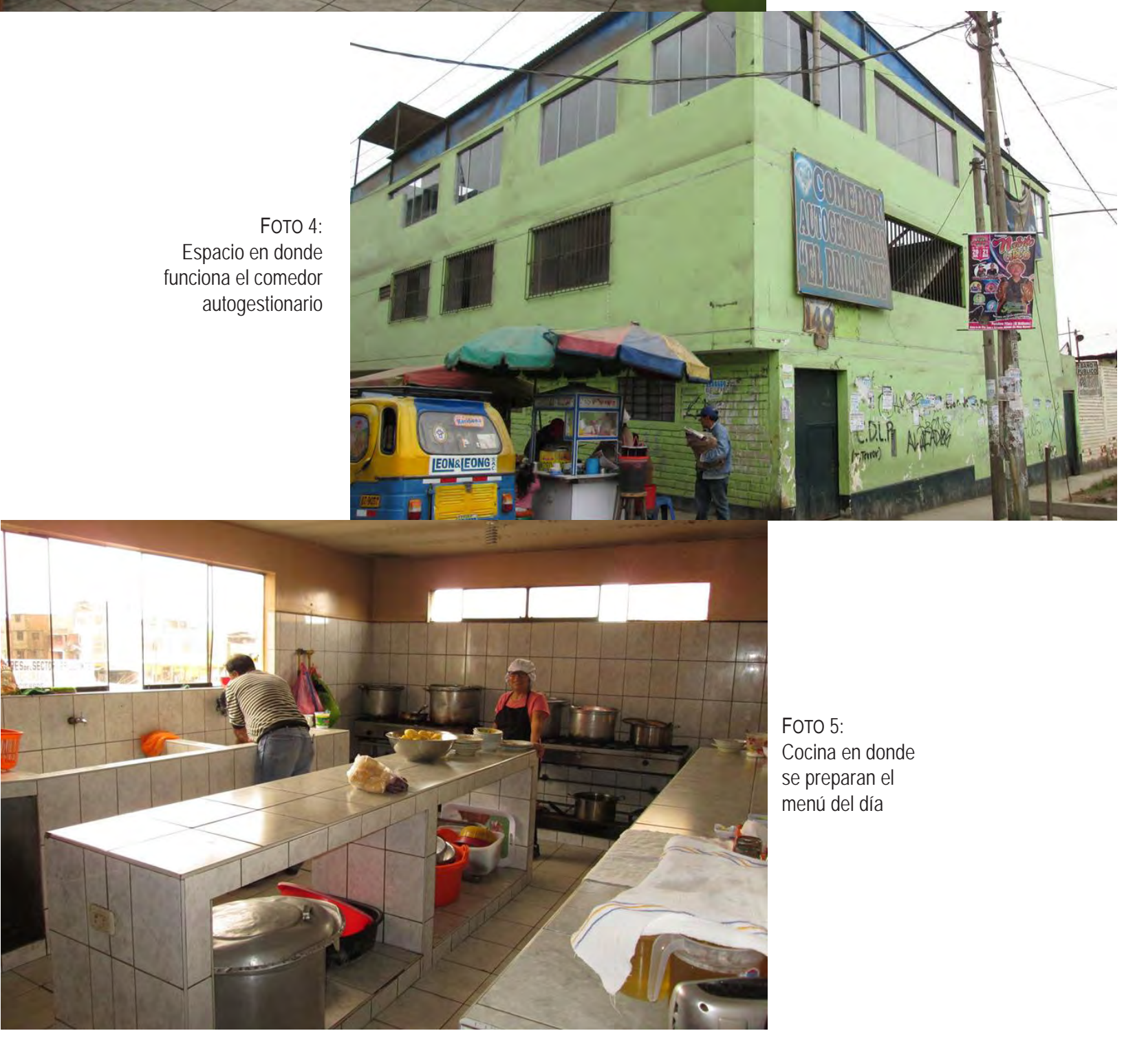




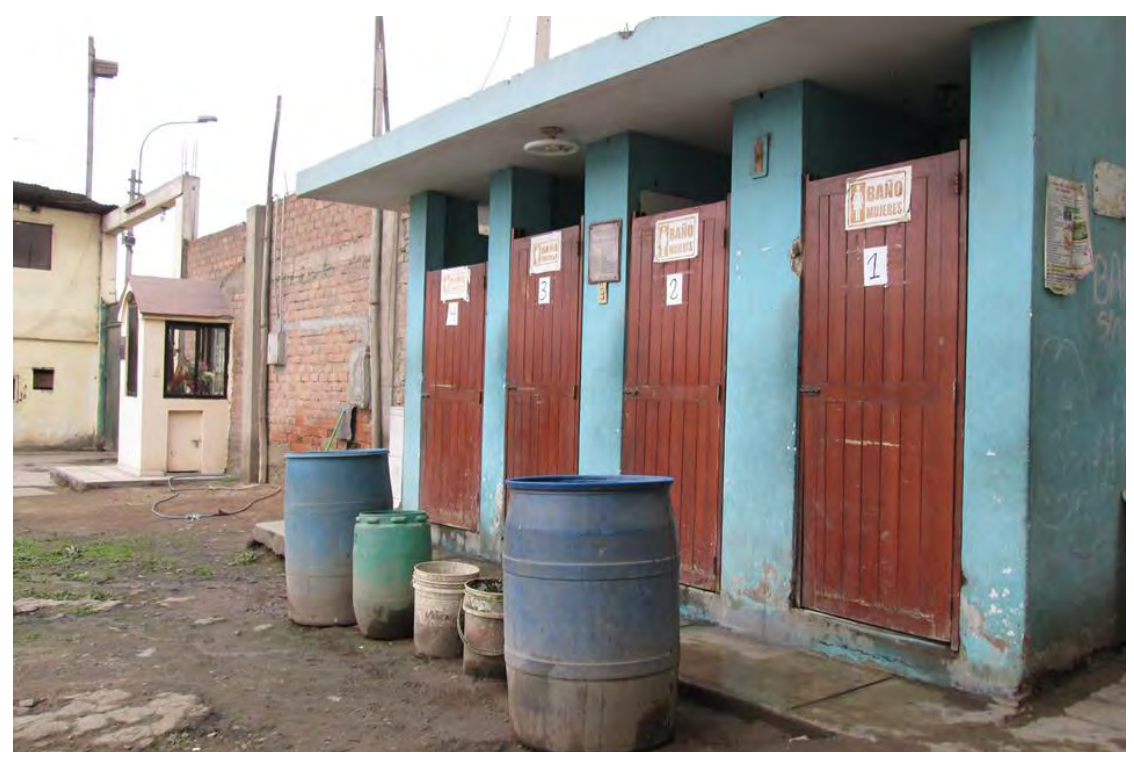

FOTO 6:

Baños que son

alquilados al

público.

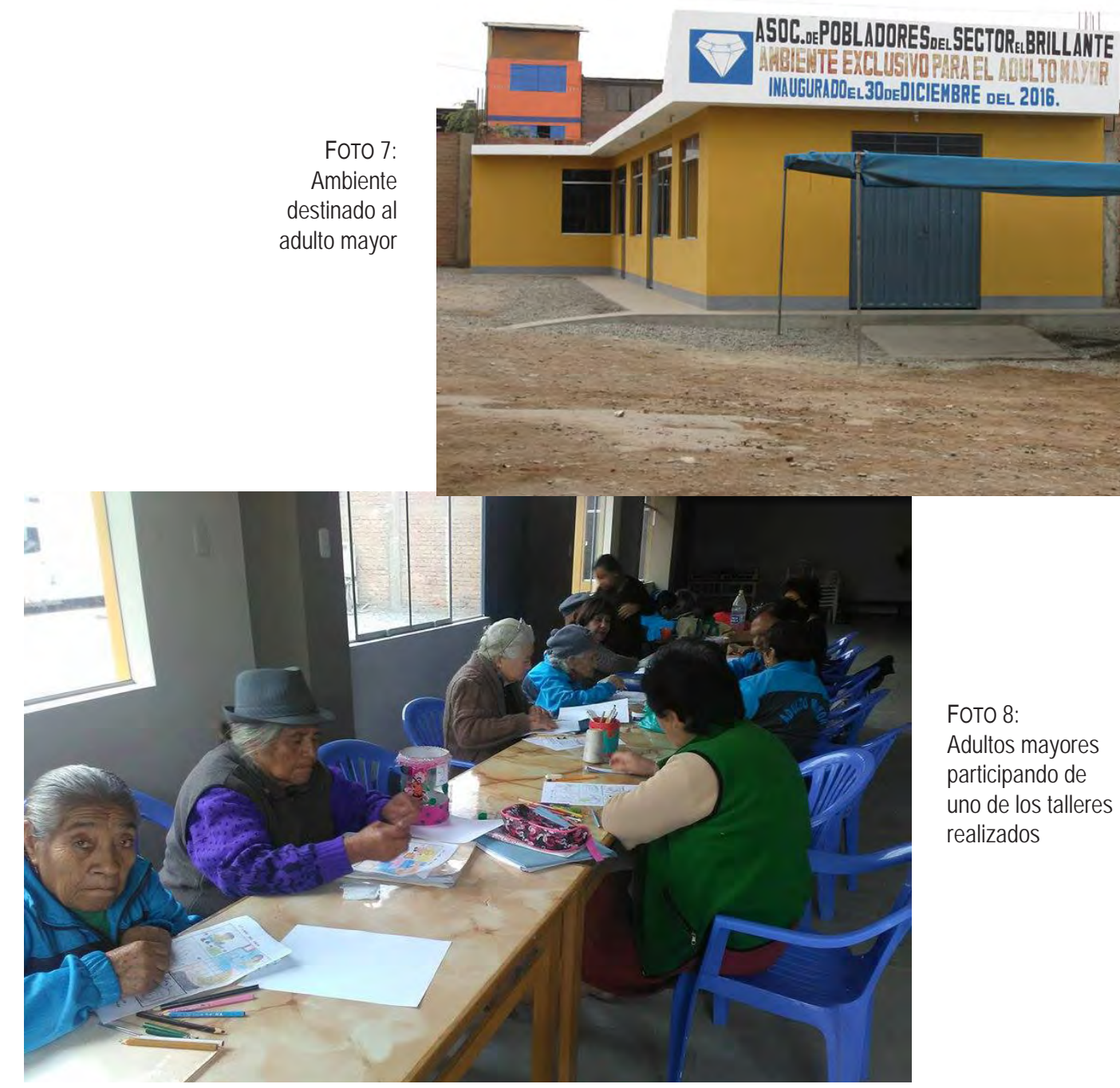




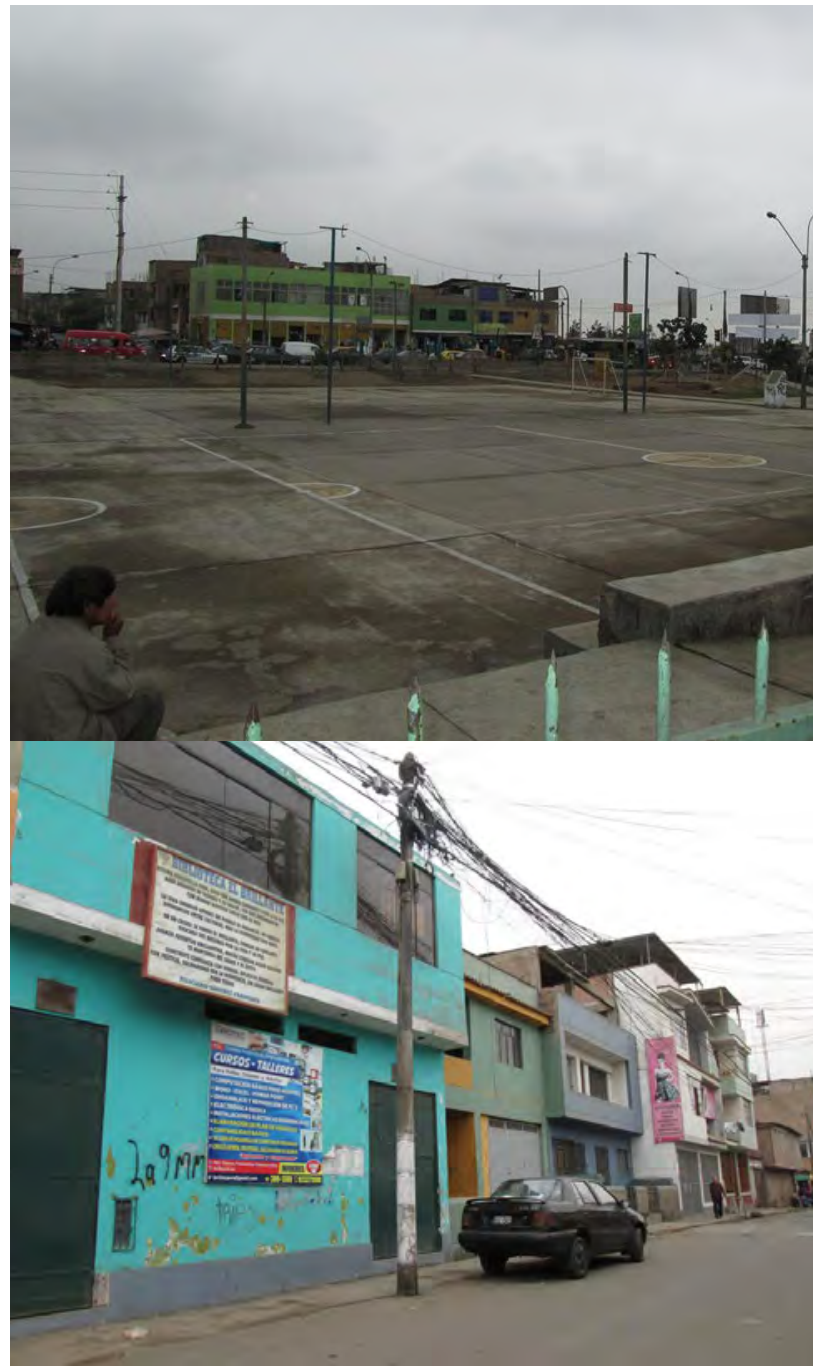

Fото 10:

Se muestra el local destinado a la Biblioteca y del Teatrín

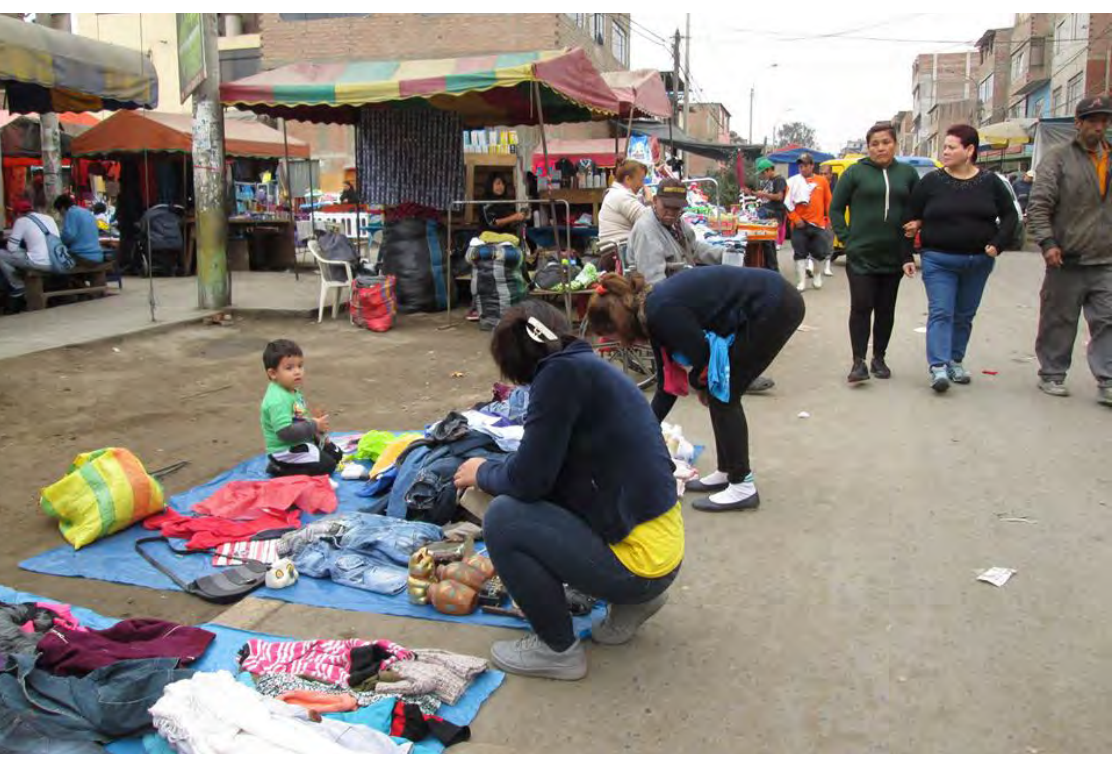

Fото 9:

Loza deportiva en donde se alquila el uso de iluminación.
FOTO 12:

Pobladores

de El Brillante

realizando

compras 